\title{
Narrativa de formação dos professores: práticas do estágio na educação infantil inclusiva
}

\author{
Jhonatan Oliveira Silva ${ }^{1}$ \\ Pedro Paulo Souza Rios ${ }^{2}$
}

\section{Resumo}

0 presente artigo tem como objetivo narrar sobre as práticas pedagógicas inclusivas desenvolvidas durante a regência do estágio em Educação Infantil. Nesta narrativa, procuro trazer propostas pedagógicas inclusivas que contribuíram para a prática do meu estágio. Nesse sentido, em linhas gerais relato a importância do/a professor/a em formação ter a sensibilidade de reconhecer a importância que tem o processo de inclusão na Educação Infantil. Através das práticas pedagógicas conseguir atingir os objetivos que pretendia para minha pesquisa, onde alcancei de fato a efetivação do processo de inclusão em uma sala de aula numa escola regular de ensino. Mas, isso só foi possível através de estudos teóricos que comtemplavam as práticas pedagógicas inclusivas durante a regência do estágio. Nesse sentido, a pesquisa alcançou outros objetivos para além daqueles já propostos dentro da pesquisa, e um desses objetivos alcançados foi à interação das crianças não deficientes, com as crianças deficientes. Dessa forma, o estágio possibilitou novas práticas pedagógicas. Diante disso, é possível dizer que o estágio se constitui momento ímpar na formação profissional docente.

Palavras chave: educação inclusiva; educação infantil; estágio docente

Recepción: 5/03/2021

Evaluación 1: 10/03/2021

Evaluación 2: 2/04/2021

Aceptación: 01/05/2021

\section{Iniciando a conversa: conhecer para incluir}

A presente pesquisa narrativa produzida através da regência do estágio em Educação Infantil proporcionou-me a possibilidade de investigar de forma mais profunda sobre a formação de professores/as, e suas metodologias em sala de aula. Foi a partir de um olhar reflexivo durante a regência que pude desenvolver uma análise sobre a formação de professores/as na Educação Infantil. A narrativa foi desenvolvida a partir de práticas pedagógicas inclusivas, desenvolvidas durante a regência do estágio. É importante ressaltar que tais reflexões estão pautadas a partir de parâmetros legais da Educação Infantil.

A Educação Infantil de forma geral com a inclusão escolar são vertentes que se tornaram pautas de discussões essências no contexto atual da educação básica brasileira. Diante disso, a narrativa do estágio tem como objetivo refletir sobre o papel da inclusão dentro do contexto da Educação Infantil, além disso, procuramos investigar de que maneira a inclusão está sendo efetivada na prática docente na sala de aula da Educação Infantil.

Esta narrativa busca através dos objetivos alcançar parâmetros, que possa promover a investigação para uma inclusão efetiva de qualidade e democrática; onde possa ocorrer dentro da escola um ambiente harmônico; de respeito entre crianças não deficientes em crianças deficientes, buscando possibilitar dentro da sala de aula; a solidariedade e a compreensão dessas crianças no contexto educacional infantil. Nesse sentido, Montoan (1996, p. 01) ressalta que "a escola tem que ser esse lugar que as crianças podem ser elas mesmas e onde as diferenças não são escondidas, mas destacadas". 
A partir do fragmento de Montoan, justifico a minha narrativa, porque desde a primeira etapa da educação básica, que é a Educação Infantil, se deveria tratar com mais pertinência o tema inclusão nas escolas regulares de ensino. Por isso, este tema sobre inclusão infantil me indagou muito, por se tratar de uma realidade vivencial. Através de memórias da Educação Infantil relembro que o processo de inclusão na infância não foi nada fácil, e o mais difícil de compreender é que uma docente naquele período contribuiu para que não desse certo este processo de inclusão infantil.

Diante dessas inquietações, durante o estágio, procurei privilegiar públicos e turmas onde tivesse a presença de crianças com necessidades educacionais especiais. A partir, das leituras de livros e artigos sobre a Educação Infantil fica evidente que por muito tempo a educação não era voltada para a criança e quando passou a existir não era prioridade, mas uma educação voltada ao assistencialismo.

Pretendo levar esses objetivos sendo eles alcançados, ou não, durante o decorrer do processo de construção da presente narrativa para o espaço acadêmico da universidade. Na sociedade atual se tem falado tanto de inclusão, mas será de fato que essa "inclusão" no contexto da Educação Infantil está ocorrendo de forma efetiva nas escolas regulares? É essa reflexão que fica tanto para olhar da comunidade como para o olhar acadêmico.

Por tanto, as bases teórico-metodológicas envolveram: leituras de livros e textos de teóricos como: Montoan (1996), Souza (2006), Gomes (2009), Rays (1996), Pimenta e Lima (2014), Salend (2008), Blanco (2004) dentre outros.

A regência do estágio em Educação Infantil ocorreu na escola municipal; Dr: Antônio Sergio Carneiro, localizado em Ponto Novo - Bahia. Os sujeitos pesquisados eram crianças não deficientes, e crianças deficientes no ensino do maternal na Educação Infantil, num período de vinte e dois (22) de julho, a quatorze (14) de agosto de 2019. Já em relação à metodologia utilizada para produção do artigo foi através das narrativas (auto) biográficas.

\section{Narrativas de formação: trajetos trilhados no desenvolvimento do estágio}

Ao vislumbrar os trajetos a serem trilhados durante o processo do estágio em Educação Infantil me coloquei num momento desafiante e, ao mesmo tempo, gratificante. A escrita da narrativa como processo final dessa trajetória se constitui, entretanto, num momento ímpar, uma vez que essa metodologia nos possibilita escrever sobre a própria caminhada durante o desenvolvimento do estágio, e também nos faz relembrar e recorrer aos conhecimentos teóricos adquiridos nos semestres anteriores, por tanto, é um momento enriquecedor para nossa formação profissional e de autonomia para nossa escrita acadêmica. Diante disso, Souza (2006) destaca que,

A escrita da narrativa potencializa no sujeito o contato com a sua singularidade e o mergulho na interioridade do conhecimento de si, ao configurar-se como atividade formativa porque remete ao sujeito para uma posição de aprendente e questiona suas identidades a partir de diferentes modalidades de registros que realiza sobre suas aprendizagens experienciais (p. 136).

Foi através das narrativas que consegui adquirir reflexões melhores e bem pensadas para o processo de construção de práticas pedagógicas inclusivas, desenvolvidas com as crianças deficientes e não deficientes dentro do contexto da Educação Infantil Inclusiva. Nesse sentido, Schmutz-Brun (1998) ressalta que,

[...] as narrativas de experiência implicam os narradores-docentes estagiários em sua subjetividade, sua historicidade, suas dúvidas e suas crenças. Partilhando suas narrativas de experiências vividas durante seu estágio de formação, os futuros professores se formam dentro de um perfil e tomam consciência de suas competências e fraquezas (p. 40). 
Diante disso, tratei de investigar no estágio como está se desenvolvendo esse processo de inclusão na prática docente na sala de aula em Educação Infantil. Assim, busquei trazer esses elementos da investigação para o parâmetro científico organizado e coerente; os desafios, medos, alegrias, conhecimento e aprendizagem, que foram proporcionados através da prática do estágio em Educação Infantil.

\section{Reflexões sobre o estágio: relação teoria-prática}

Durante o processo da regência do estágio foi importante refletir acerca da relação teoria-prática. Desde o início da formação em pedagogia é perceptível às relações estabelecidas entre teoria e prática, mas só conseguimos entender de fato está análise a partir dos estágios. Contudo, foi através dos textos teóricos problematizados nas durante as aulas de estágio, que passei a criar um arcabouço de conhecimentos para desenvolver a teoria na prática pedagógica inclusiva. Diante disso, as aulas foram sempre interativas, dinâmicas, compreensível e auxiliadora na organização em que contribuiu de maneira muito importante para com o estágio em sua relação teórico-prática. Segundo Rays (1996),

\footnotetext{
É a atividade teórico-prática do homem que motiva e promove, criticamente, transformações na realidade objetiva e no próprio homem. Nesse sentido pode-se afirmar que é a atividade (o conhecimento teórico-prático do homem) que assegura ao ser humano as condições socioculturais e as bases materiais de sua própria existência. Desse modo, a teoria - o conhecimento - é um momento da prática - ação-, assim como a prática é um momento da teoria e do próprio pensar (p. 37).
}

Percebemos, portanto, a importância que tem as aulas de estágio, uma vez é a partir das mesmas que ficou nítida a reflexão entre a teoria e prática para desenvolver as etapas do estágio. Desse modo, é importante frisar também as memórias que fazemos para que possamos restabelecer um elo entre o componente curricular de estágio em Educação Infantil com as matrizes curriculares dos semestres anteriores. As matrizes curriculares como; a Psicologia, Sociologia, Ludicidade e Educação Inclusiva são áreas do conhecimento fundamentais da prática pedagógica inclusiva.

A organização das aulas de estágio foram importantes no processo de construção da aprendizagem, pois, eram textos teóricos com uma linguagem científica, mas que essas linguagens eram claras e objetivas de compreensão sobre a Educação Infantil, e acerca disso, se tornaram "ferramentas" para elaboração do projeto de pesquisa; com teóricos que tratam de estágio, e para narrativa como produto final; foram trabalhados em sala de aula os teóricos que discutiam sobre as narrativas sejam elas (auto)biográficas, ou não, e sobre as importâncias que as mesmas tem para pesquisa acadêmica, e essas aulas a meu ver era interessante porque todos os/as alunos/as da sala colocavam seu ponto de vista, e de certa forma essas opiniões diferentes me ajudaram na elaboração e na execução da minha pesquisa narrativa.

Essas aprendizagens nas aulas de estágio me fizeram refletir o quanto é importante às interações, porque me ajudou bastante na perspectiva de me tornar um pesquisador na minha área de estudo; sobre a inclusão infantil.

\section{Observação: fazer pedagógico que antecede a regência do estágio}

0 período que antecede a regência do estágio é de extrema importância para a formação do/a profissional, visto que se trata de uma reflexão crítica sobre a importância de investigar e de interagir com as crianças e, nesse caso específico principalmente, uma vez que na sala de aula a qual fiz a minha observação alguns desses sujeitos têm necessidades educacionais especiais, logo são eles/as o foco principal da minha pesquisa. As crianças com necessidades 
educacionais especiais normalmente demoram um tempo maior que as outras crianças para poder confiar no professor/a por isso, a importância de já no período de observação começar esse processo de interação.

É importante ressaltar também a necessidade do/a pesquisador/a está buscando as informações acerca do Plano Político Prático Pedagógico - PPP da escola para que possamos saber de fato qual é o real sentido da instituição em relação à inclusão escolar. Nesse sentido, Gomes (2009, p.75) afirma que,

Ao observar a prática de um educador, invariavelmente diferente de um lugar para outro, por exemplo, o estagiário precisa ter condições de apreender a(s) teoria(s) que a sustenta(m) e poder realizar uma leitura pedagógica para além do senso comum, tendo como base teorias e fundamentos estudados e confrontados com as situações da prática profissional para a produção de alternativas e de novos conhecimentos. Estamos referindo-nos às práxis, à capacidade de articular dialeticamente o saber teórico e o saber prático.

Através da observação pude perceber que a estrutura física da escola não é voltada para Educação Infantil e muito menos para a inclusão, por exemplo, a falta de banheiros adaptados, portas que permitam a passagem da cadeira de rodas, barras de apoio, rampas, no mobiliário da escola, falta de mesas e cadeiras adaptadas de acordo com as características dos alunos/as, por exemplo. Some-se a tudo isso a ausência de profissionais especializados/as na área, já que a inclusão necessita de professor/a especializado em educação especial, psicólogo/a, fisioterapeuta/o, fonoaudiólogo/a, entre outros/as. As dificuldades anteriormente citadas mostram que a inclusão escolar precisa de investimentos financeiros, o que também acaba se tornando como empecilho.

Assim, ressalto que o período de observação desenvolveu em mim ainda mais a vontade de realizar meu estágio nessa área de inclusão infantil, pois, assegurou o conhecimento de todo o contexto escolar bem como pude identificar as características dos alunados como o todo.

\section{Estágio docente na Educação Infantil: desafios para trabalhar a Educação Inclusiva}

O primeiro estágio do curso de licenciatura em pedagogia foi direcionado aos espaços não formais. Já o segundo estágio do curso de licenciatura em pedagogia foi direcionado à primeira etapa da educação básica: a Educação Infantil. Diante disso, a Lei de Diretrizes Bases da Educação Nacional para a Educação Infantil (2010, p. 15) é colocada como:

Primeira etapa da educação básica oferecida em creches e pré-escolas, as quais caracterizam como espaços institucionais não domésticos que constituem estabelecimentos educacionais públicos ou privados que educam e cuidam de crianças de 0 a 5 anos de idade no período diurno, em jornada integral ou parcial, regulados e supervisionados por órgão competente do Sistema de ensino e submetidos a controle social.

0 início do estágio foi um momento desafiante, mas apesar do desafio sabia que o estágio seria uma oportunidade de aprendizagem enriquecedora para minha formação profissional e acadêmica. 0 estágio em Educação Infantil é o ponto de partida fundamental para quem deseja atuar especialmente na área da Educação Infantil. Segundo Pimenta e Lima (2014),

[...] o estágio se constitui como um campo de conhecimento, o que significa atribuir-lhe um estatuto epistemológico que supera sua tradicional redução à atividade prática instrumental. Enquanto campo de conhecimento, o estágio se produz na interação dos cursos de formação com o campo social no qual se desenvolvem as práticas educativas (p. 06).

0 estágio se configura enquanto grande oportunidade para que futuros/as pedagogos/as possam construir a nossa identidade profissional, e ao mesmo tempo em que é um momento ímpar de amadurecimento tanto para a formação acadêmica como para o aspecto profissional. 
Para mim foi de suma importância às aulas de estágio, visto que possibilitou maior aprofundamento teórico para que pudéssemos elaborar práticas coerentes com realidade das crianças e para poder executa-las, enfim passei por um processo que fará parte da minha identidade como profissional.

O estágio na Educação Infantil deu a oportunidade de investigar algo que já era de interesse pessoal há bastante tempo sobre o processo de inclusão na Educação Infantil. Assim, estar adentrado neste espaço, que é tão importante para o contexto social, e que ao mesmo tempo se torna importante para minha formação acadêmica, faz-me refletir a responsabilidade que tinha de ter naquele espaço escolar, visto que sempre procurava através de estudo teórico o melhor para minhas práticas pedagógicas, para que de fato acontecesse este processo de inclusão. Desse modo, a formação em Educação Infantil requer, da docência, saberes que façam parte da realidade social dos educandos/as. Nesse sentido, Rocha (1999) relata que,

\begin{abstract}
Enquanto a escola se coloca como espaço privilegiado para o domínio dos conhecimentos básicos, as instituições de educação infantil se põem, sobretudo, com fins de complementaridade à educação da família. Portanto, enquanto a escola tem como sujeito o aluno e como o objeto fundamental o ensino nas diferentes áreas através da aula; a creche e a pré-escola têm como objeto as relações educativas travadas no espaço de convívio coletivo, que tem como sujeito a criança de 0 a 6 anos de idade (ou até o momento que entra na escola) (p. 62).
\end{abstract}

Ao fazer essa análise no campo da Educação Infantil é possível perceber a importância do fazer pedagógico com as realidades sócias dos/as educandos/as. Nesse sentido, durante o processo do estágio sugiram algumas situações, que me fizeram recorrer as minhas memórias em relação as matrizes curriculares dos semestres anteriores, como no caso da psicologia e principalmente da Educação Inclusiva. Diante disso, passei a refletir o porquê de algumas matrizes curriculares dessas, não foram próximas a este semestre, mas conforme fui relembrando essas memórias, e através das leituras de livros, e artigos consegui desenvolver de forma "suscita" à minha prática docente.

É importante ressaltar que o/a professor/a em formação busque conhecimentos novos para que tenha domínio dessas aprendizagens, e que possa refletir acerca das suas próprias ações e atitudes que terá que desenvolver em quanto estagiário/a. Diante disso, Imbernón (2006: p. 44) "afirma que "a formação é um elemento importante de desenvolvimento profissional, mas não é o único e talvez não seja decisivo", pois considera um conjunto de fatores".

Concordo com Imbernón, porque quem faz a sua formação docente valer tal "reconhecimento" é o próprio professor/a através de práticas pedagógicas aceitáveis para o desenvolvimento do aluno/a no contexto escolar como o todo. Desse modo, a minha pesquisa teve abordagem qualitativa porque é um método de investigação científica que se foca no caráter subjetivo do objeto analisado, e terá como corpo de desenvolvimento o estudo de caso.

Diante disso, o estudo de caso me fez refletir para entender melhor os fenômenos individuais, os processos organizacionais e políticas sócias. Por tanto, essa metodologia foi utilizada para que me pudesse ter uma compreensão melhor sobre as ações e os motivos que levaram a determinados objetivos. Segundo Yin $(2015$, p. 03) "o estudo de caso é uma estratégia de pesquisa que compreende um método que abrange tudo em abordagens especificas de coletas e análise de dados". Desse modo, é o método que melhor se encaixa com abordagem qualitativa da minha pesquisa como o todo.

\title{
Práticas pedagógicas inclusivas: ponto principal do estágio
}

A escrita da narrativa me deu a possiblidade de relembrar as minhas memórias de infância, e que ao mesmo tempo me fez amadurecer o processo de formação docente por meio do método (auto) biográfico. Narrar as minhas experiências de estágio foi muito desafiante, visto 
que gerou um processo desencadeado a partir de várias reflexões sobre a minha formação acadêmica, e nesse sentido, sempre procurava me colocar como pesquisador/investigador da minha área de pesquisa, e foi através de memórias da Educação Infantil que pude desenvolver o meu amadurecimento humano e profissional em formação. Souza (2007) ressalta que,

Trabalhar com a memória, seja a memória institucional ou a do sujeito, faz emergir a necessidade de se construir um olhar retrospectivo e prospectivo no tempo e sobre o tempo reconstituído como possibilidade de investigação e de formação de professores (pp. 63-64).

Ao relembrar as memórias da minha Educação Infantil passo a refletir, o quanto ainda preciso de experiência como formador/a profissional e como pesquisador/a na área da Educação Infantil inclusiva, procurando sempre desenvolver o melhor de mim e para o meu público de crianças especiais.

\section{Etapa por etapa do fazer pedagógico inclusivo: um planejamento necessário}

O planejamento tem como objetivo fazer com que o/a professor/a tenha a tranquilidade para poder desempenhar a sua aula em um ambiente mais harmônico. Porém, quando o público se trata de crianças, é preciso que os conteúdos planejados sejam de caráter repetitivo uma vez que a repetição ajuda as crianças terem uma noção de quais tarefas elas irão praticar naquela determinada aula, e que depois de realizar aquela atividade será desenvolvida outra, e assim os mesmos irão se encachando aos poucos no planejamento do/a professor/a.

Diante disso, Vasconcellos (1995, p. 143) aborda que, "o planejamento pode ser definido como uma forma metodológica utilizada nas escolas educativas de ensino para da suporte necessário ao trabalho do professor/a, visto que garanta o acesso de qualidade para as crianças". Compreendo, portanto, que o planejamento contribui para que as ansiedades das crianças sejam controladas de forma mais tranquila e suscita dentro da sala de aula.

A partir do planejamento comecei a executar às minhas práticas pedagógicas inclusivas na regência do estágio. Beyer (2008, p. 102) já afirma que, “O professor em sala de aula é peça fundamental para que ação educativa junto aos alunos/as com necessidades educacionais especiais tenha margem razoável de sucesso". Estou de acordo, com Beyer se o/a professor/a em formação não se coloca como peça chave desse processo de ensino, jamais o processo de inclusão escolar irá ocorrer de forma lúcida dentro da sala de aula.

Assim, elaborei e executei as tarefas com as crianças deficientes e também com aquelas que não eram deficientes, e tudo estava de acordo com o planejamento da escola: acolhida, café, oração, hora das músicas infantis, hora da leitura de uma história infantil, os eixos desenvolvidos estão de acordo com os referenciais teóricos para Educação Infantil, principalmente para inclusão. Visto que, sempre elaborava minhas propostas pedagógicas inclusivas de modo que ocorresse uma ligação "amigável" com o planejamento estabelecido pela Instituição de Ensino.

Constantemente, buscava eixos práticos variados para com as crianças: Coordenação motora, raciocínio lógico, reconhecendo as vogais, os números simples, as cores primárias e secundárias, e principalmente as atividades lúdicas que tinha o papel de contemplar essa relação afetiva das crianças não deficientes com crianças deficientes, sendo o maior foco da minha proposta de estágio a inclusão no contexto infantil. Nessa direção, Salend (2008) destaca que,

É necessário o respeito e à aceitação dos pontos fortes e desafiadores dos alunos/as assim como da diversidade existente em sala de aula. Ele afirma que os professores não podem ensinar seus alunos/as desconsiderando diversos fatores que os tornam indivíduos únicos, já que fatores como raça, gênero, língua, comprometimentos e nível econômico interagem e influenciam o desempenho acadêmico e social dos alunos/as (p. 103). 
De acordo, com Salend, refletir que para além da minha prática pedagógica inclusiva, para que possa chegar a uma sala de aula que seja realmente inclusiva, a mesma tem que está inserida na base da aceitação e equidade, que valorizam a capacidade que todas às crianças possuem para aprender a contribuir com a sociedade.

Diante disso, destaco que nas lembranças da minha Educação Infantil não obtive êxito como aluno no processo de inclusão escolar, dessa forma agora como professor em formação pretendo atingir o objetivo de fazer com que essas crianças com necessidades educacionais especiais tenham sua própria autonomia, e que se sintam inseridos/as no ambiente escolar com os outros sujeitos.

A prática do estágio realizada com a maior aceitação por parte das crianças deficientes e também daquelas que não eram deficientes, foram as cores primárias/secundárias, que foram realizadas através de copos descartáveis coloridos, bandejas de ovos coloridas e palitos de picolé também coloridos.

As práticas inclusivas mencionadas acima tiveram como objetivo fazer com que a criança internalize as cores nos seus respectivos raciocínio lógico, e também saber analisar de forma subjetiva/interpretativa o que está praticando. Blanco (2004, p. 101), "destaca que, todos os alunos/as apresentam características físicas, comportamentais e emocionais próprias, sendo que devido à existência destas, uma prática de ensino voltada para um conjunto homogêneo de crianças não alcança o êxito". Com base na teoria de Blanco, procurei variar as minhas práticas pedagógicas inclusivas, e que todas eram voltadas o máximo possível às especificidades de cada alunado.

Nessa perspectiva, foi imprescindível focar nessa proposta inclusiva, pois constatei que as crianças com necessidades educacionais especiais conseguiram através das "práticas inclusivas" desenvolverem com mais facilidade esses processos de interações com as outras crianças, e que posteriormente haveriam de atingir as práticas pedagógicas propostas. Por exemplo, o eixo das vogais foi trabalhado com a manipulação de objetos; como uso dos copos descartáveis contendo as letrinhas das vogais, as cores, os numerais de 0 a 5 , as boas maneiras de interação com os colegas e os dias da semana.

É importante frisar, que as crianças não deficientes interagiam com naturalidade com as crianças deficientes, e em nenhum momento ocorreu essa separação entre elas, na verdade as mesmas ajudavam umas às outras para poder desenvolver as atividades propostas. Nesse sentido, fiz prevalecer os eixos das atividades inclusivas propostas, mas obedecendo sempre às normas estruturantes da Base Nacional Comum Curricular. Segundo a BNCC (2017).

\begin{abstract}
A Base Nacional Comum Curricular (BNCC) é um documento de caráter normativo que define o conjunto orgânico e progressivo de aprendizagens essenciais que todos os alunos devem desenvolver ao longo das etapas e modalidades da Educação Básica. Aplica-se educação escolar, tal como define o conjunto orgânico e progressivo de aprendizagens essenciais que todos os alunos devem desenvolver ao longo dessas etapas e modalidades da Educação Básica. [..] orientadas pelos princípios éticos e estéticos traçados pela Diretrizes Curriculares Nacionais para Educação Básica (DCN), a BNCC soma-se aos propósitos que direcionam a educação brasileira para a formação humana integral e para construção de uma sociedade justa, democrática e inclusiva (p. 5).
\end{abstract}

De toda forma, tais propostas tornam-se ferramentas para desenvolver a educação de um modo que trouxesse sentido. Portanto, pude encaminhar o meu estágio visando garantir direitos de aprendizagem e desenvolvimento na Educação Infantil Inclusiva.

Nesse sentido, surgiram algumas reflexões a partir das interações das crianças não deficientes, com as crianças deficiente durante as execuções das atividades propostas. Por exemplo, o modo como elas ajudavam umas as outras me fez pensar e concluir que a maldade de separar as pessoas consideradas "normais" daquelas que tem alguma necessidade educacional 
especial está nas práticas dos adultos e não na interação das crianças. Diante disso, Salend (2008) destaca que,

A comunidade e a colaboração, explicando que a inclusão escolar só pode ser efetivada com o esforço e o envolvimento de professores, dos demais profissionais envolvidos com a educação do aluno/a, dos próprios alunos/as, dos familiares e da comunidade. Salend defende que esses personagens precisam trabalhar juntos, compartilhando recursos, responsabilidades, habilidades, decisões e defesa pelos direitos dos alunos/as (p. 104).

Entendemos, dessa maneira, que só conseguiremos de fato fazer o processo de inclusão funcionar nas escolas regulares de ensino, e na sociedade, se as pessoas que estão envolvidas na vida da criança com necessidade educacional especial começarem a participar ativamente dos processos educativos e sociais, para poder a partir de então colocar em prática todo aquilo que a lei assegura para que essas crianças "possam" se sentir inseridos/as tanto no contexto escolar como também no social.

\section{Considerações finais: confirmando a inclusão}

O estágio possibilitou grandes experiências para minha formação acadêmica. Os desafios durante período da regência foram muito, mas as aprendizagens adquiridas junto com as crianças, com o professor orientador, com os amigos/as de sala de aula, com a regente. Faz com que essas pessoas mencionadas se tornem fundamentais na contribuição para meu processo de formação profissional.

Através das minhas práticas pedagógicas inclusivas conseguir atingir os objetivos que pretendia para a pesquisa, onde alcancei de fato a efetivação do processo de inclusão em uma sala de aula numa escola regular de ensino. Mas, só foi possível através de estudos teóricos que comtemplavam as minhas práticas pedagógicas durante a regência do estágio.

Nesse sentido, a minha pesquisa alcançou outros objetivos para além, daqueles já propostos dentro da pesquisa, e um desses objetivos alcançados foi à interação das crianças não deficientes, com as crianças deficientes, em que ambas faziam as atividades propostas juntas e sempre ajudando umas às outras de forma natural e sem nenhuma separação. Dessa forma, o estágio me deu a possiblidade de fazer totalmente diferente do que havia acontecido na minha Educação Infantil, onde o processo de inclusão não fez sentindo nenhum na minha aprendizagem como educando.

Já dizia: Montoan (1996, p. 01), “as diferenças das crianças na escola não podem ser escondidas, mas destacadas". Em cima dessa afirmação acredito que este trabalho contribuiu para que nós professores em formação de forma geral possamos reconhecer o valor que a criança com necessidade educacional especial tem, e que a mesma não pode ficar escondida, mas essa criança precisa ser o destaque da sala assim como os demais sujeitos.

Desse modo, é preciso aprender mais, e para mim aqui não é o final. Pretendo aprender mais sobre inclusão, e está me sentido cada vez mais desafiado a adquirir mais conhecimento às minhas práticas e a cada dia me constituir um pesquisador na área inclusiva.

\section{Referências}

Blanco, R. A. (2004). Educação especial e inclusão escolar - história e fundamentos. /Atenção à diversidade na sala de aula e as adaptações do currículo. In: Coll, C.; Marchesi, A.; Palacios, J. A. (Org.). Desenvolvimento psicológico e educação: transtornos de desenvolvimentos e necessidades educativas especiais. Porto Alegre: Artmed.

Beyer, H. O. (2008). Educação especial e inclusão escolar - história e fundamentos. /O projeto político pedagógico da educação inclusiva e a gestão educacional: reflexões com a área de educação 
especial da Secretaria de Educação do Estado do Rio Grande do Sul. In: Freitas, S. N. (Org.). Tendências contemporâneas de inclusão. Santa Maria: Ed. da UFSM.

Brasil, Ministério da Educação. Secretaria da Educação Básica. Diretrizes curriculares nacionais para a Educação Infantil/Secretaria de Educação Básica, Brasília, MEC, SEB, 2010.

Gomes, M. (2009). Formação de professores na educação infantil. São Paulo: Cortez, (Coleção docência em formação. Série educação infantil).

Guía Prático da BNCC, (2017). [Internet] Disponível em: <Revista Construir Notícias. Ano 16. Julho/agosto 2017. Distribuição dirigida. Circulação nacional. № 95. ISSN 2236-3505>. Acesso em: 02/09/2019.

Imbernón, F. (2006) Didática - Formação docente e profissional. /Formar-se para a mudança e a incerteza. $6^{\mathrm{a}}$ ed. São Paulo: Cortez.

Montoan (2019), Conhecer para Incluir. [Internet] Disponível em: <https://www.sympla.com.br/i-ciclo-de-palestras-napne---conhecer-para-incluir__115161>. Acesso em: 02/09/2019.

Pimenta, S,; Lima, M. (2005) Estágio e docência: diferentes concepções. Revistas Paeses-vol. 3e4.

Rays, O. A. (1996) A relação teoria-prática na didática escolar crítica. In VEIGA, I.P.A. (org). Didática: o ensino e suas relações. Campinas: Papirus.

Rocha, E. (1999) A Pesquisa em Educação Infantil no Brasil: Trajetória recente e perspectiva de consolidação de uma pedagogia. UFSC/CDE/NUP.

Salend, S. J. (2008) Educação especial e inclusão escolar - história e fundamentos. /Creating inclusive classrooms: effective and reflective practices. 6 . ed.

Schmutz-Brun, C. (1998) Les histoires de vie comme processus de connaissance de son oralité/écriture et processus Formate ur de dynamiques langagières. Communicati on au col lo que de ren nes: cul tu res et mou ve ments.

Souza, E. (2006) Pesquisa Narrativa e (auto) biográfica: interfaces metodológicas e formativas. Tempos, narrativas e ficções: a invenção de si. Porto Alegre; EDIPURCS.

Vasconcellos, C. D. S. (1995) A importância do Planejamento no contexto escolar. [Internet] Disponível em:

https://portal.fslf.edu.br/wp-content/uploads/2016/12/A-IMPORTANCIA-DO-PLANEJAMENT 0.pdf.

Yin, R. K. (2015) Estudo de caso. [Internet] Disponível em:

<https://www.infoescola.com/sociedade/estudo-de-caso/.htm> Acesso em: 02/09/2019.

\section{Notas}

${ }^{1}$ Universidade do Estado da Bahia, Brasil, jhonatanoliveirasilva704@gmail.com

${ }^{2}$ Universidade do Estado da Bahia - Uneb, peudesouza@gmail.com 